\section{Health and the Gut Microbiome: Who Knew?}

A s I write, we are all in lockdown facing a coronavirus pandemic unlike anything we have experienced before. I hope by the time you read this, our world is on the road to recovery. While this is a pernicious virus, we must remember that not all germs are bad. For example, before the pandemic, I was learning more about a new frontier in biomedical science, the microbiome, especially the gut microbiome. Who ever imagined the gut microbiome would actually become interesting? And important? I'll admit that in my early years, when I studied colon carcinogenesis, I did wonder about this. Of course, analyzing the entire microbiome wasn't even possible then, but now that we have ways to define and analyze the enormous data produced in those studies, many trends are emerging. Furthermore, fecal microbiota transplants are now approved for use in certain conditions, such as refractory Clostridium difficile.

Currently, research suggests that our microbiome may dictate whether we are at risk for obesity, whether we get cancer in the first place, and importantly, whether we respond to treatment and ultimately survive the disease. ${ }^{1}$ I find that mind-blowing. It opens up so many possibilities for investigation and application to human health.

Just imagine if we could identify, early in someone's life, a cancer-prone microbiome that we could manipulate into a cancer-resistant microbiome. Of course, it would never be that simple, and manipulating a cancer-prone microbiome in the gut might alter the cancer-resistant microbiome in another organ, like skin. There is so much we don't know, but the possibilities are endless.

I'm particularly intrigued by work that suggests that altering the gut microbiome may possibly improve a patient's odds of responding to immunotherapy or decrease their likelihood of developing graft-versus-host disease after stem cell transplant. ${ }^{2,3}$ Understanding the reasons for this is "beyond my pay grade," but the clinical data are really encouraging. And the data provide hope that we could manipulate the gut microbiome to improve therapy in cancers that currently do not respond to this transformative approach.

I do have some concerns about quality control in these sorts of studies, as well as about safety. Regarding the former, how much do we know about normal variation in the gut microbiome? For example, if I go on a low-carbohydrate diet, what happens? If I eat spicy Indian food the night before I submit my sample, does it affect the result? I understand that standard procedures have been developed for collection and storage, but if I send the same sample to 5 different laboratories, will I get the same result from all 5 ? Regarding safety, deaths have occurred after fecal microbiota transplant due to toxic Escherichia coli. ${ }^{4}$ Could other dangerous conditions arise? I assume the FDA is on top of this, but it does seem like mistakes can happen more easily when you are harvesting fecal microbes from supposedly health volunteers.

Still, I believe we can work through these issues. In the meantime, have a little respect for your gut microbiome. It might be the best asset you have!

\section{References}

1. Schwabe R, Jobin C. The microbiome and cancer. Nat Rev Cancer 2013;13:800-812.

2. Gopalakrishnan V, Spencer CN, Nezi L, et al. Gut microbiome modulates response to anti-PD-1 immunotherapy in melanoma patients. Science 2018;359:97-103.

3. Jenq RR, Taur Y, Devlin SM, et al. Intestinal Blautia is associated with reduced death from graft-versus-host disease. Biol Blood Marrow Transplant 2015;21:1373-1383.

4. Grady D. Fecal transplant is linked to a patient's death, the FDA warns. The New York Times. June 14, 2019. Accessed March 6, 2020. Available at: https://www.nytimes.com/2019/06/13/health/fecaltransplant-fda.htm

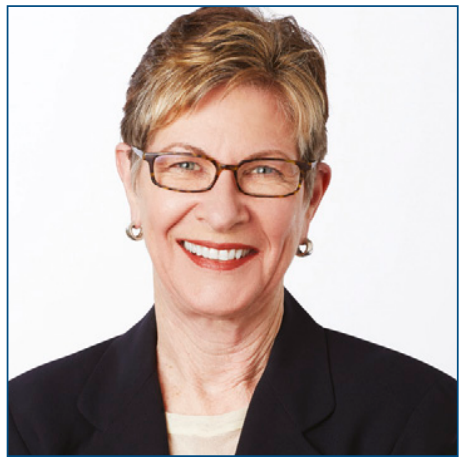

MARGARET TEMPERO, MD

Margaret Tempero, MD, is a Professor of Medicine and Director of the UCSF Pancreas Center and editor-in-chief of JNCCN. Her research career has focused on pancreatic ductal adenocarcinoma, especially in the area of investigational therapeutics. Dr. Tempero has served on the ASCO Board of Directors and as ASCO President. She currently serves on the ASCO Conquer Cancer Foundation Board. She codirected the AACR/ASCO Methods in Clinical Cancer Research and taught this course and similar courses in Europe and Australia. She was founding Chair of the $\mathrm{NCl}$ Clinical Oncology Study Section and served as a member and Chair of the $\mathrm{NCl}$ Board of Scientific Counselors Subcommittee A. She is a member of the Scientific Steering Committee and Chair of the Clinical and Translational Study Section for the Cancer Prevention \& Research Institute of Texas. She is or has been on the Scientific Advisory Boards of the Lustgarten Foundation, the Pancreatic Cancer Action Network, the V Foundation, The Alberta Canada Cancer Board, and the EORTC. She served as a member of the Oncology Drug Advisory Committee for the FDA. She has served as Deputy Director and Interim Director for the UNMC Eppley Cancer Center. She is Chief Emeritus of the Division of Medical Oncology at UCSF. She served as the founding Deputy Director and was later Director of Research Programs at the UCSF Helen Diller Family Comprehensive Cancer Center.

doi: $10.6004 /$ jnccn.2020.0018

The ideas and viewpoints expressed in this editorial are those of the author and do not necessarily represent any policy, position, or program of NCCN. 